\title{
Studying Ignition Delay Time of Lubricant Oil Mixed with Alcohols, Water and Toluene in IQT and CVCC
}

\author{
Author, co-author (Do NOT enter this information. It will be pulled from participant tab in \\ MyTechZone) \\ Affiliation (Do NOT enter this information. It will be pulled from participant tab in MyTechZone)
}

\begin{abstract}
The auto-ignition of liquid fuel and lubricant oil droplets is considered as one of the possible sources of pre-ignition. Researchers are continually finding new ways to form advanced lubricant oil by changing its composition and varying different oil additives to prevent the occurrence of this event. In this study, three sets of mixtures are prepared. The first set of mixtures was prepared by adding different alcohols namely ethanol, methanol and propanol, to the commercial lubricant oil (SAE $15 \mathrm{~W}-40$ ) in ratio of $1-5 \%$ by vol The second set of mixtures were prepared by mixing SAE $15 \mathrm{~W}-40$ with aforementioned alcohols ( $1 \%$ vol.) and $\mathrm{H}_{2} \mathrm{O}$ (1\% vol.). Lastly, third set of mixtures were prepared by adding SAE $15 \mathrm{~W}-40$ in toluene ( $1 \%-5 \%$ by vol.). Two experimental setups were used in the current work. An Ignition Quality Tester (IQT) was used investigate the mixtures' ignition delay time (IDT) following standard ASTM D6890 procedure, while a constant volume combustion chamber (CVCC) was used to investigate the combustion characteristics of burning of a suspended single oil droplet. For the CVCC, experiments were carried out in an ambient air environment at $300{ }^{\circ} \mathrm{C}$ with varying pressure ranging from 4 bar - 22 bar at 6 bar interval pressures.
\end{abstract}

IDT of lubricant oil was considered as the base IDT, which was compared to those of other mixtures. Addition of alcohols and water in lubricant oil showed a significant increase in IDT compared to other mixtures. However, the addition of toluene resulted in a decrease in IDT. Among the alcohols, methanol addition showed highest IDT compared to ethanol. However, alcohols had to be added $>4 \%$ by vol., to show a significant increase in IDT compared to pure lubricant oil.

\section{Introduction}

It is well known that the fuel composition, lubricant oil formulation, and other engine parameters can trigger the pre-ignition (PI) event in a downsized boosted gasoline direct injection engines [1]. Previously, Amann et al. [2] showed an increase in PI occurrence with fuel blends with high levels of aromatics. Among many of these factors, engine lubricant oil-induced PI events have got the attention of several researchers. These lubricant oils have high cetane numbers (CN) ranging from 78 to 89 . Under certain conditions, the lubricant oil droplets released from the cylinder liner create a localized ignitable region which is susceptible to ignition prior to the defined spark timing [3]. Dahnz et al. [4] reported that lubricant oil droplets scraped off the cylinder liners during fuel injection is the most probable cause of PI occurrence.

Studies from Toyota Motors showed that these scraped off lubricant oil droplets when exposed to the combustion chamber has a minimal possibility to ignite in the same cycle because of low temperature.

Page 1 of 7
But it can become a source of ignition in the next cycle after it is heated due to combustion [5]. Additionally, they also reported that the occurrence of PI is significantly affected by the types of base oils and additives used in engine oil. In their findings, addition of MoTDC or ZnDTP had a suppressing effect on PI event occurrence while $\mathrm{Ca}$ detergent, $\mathrm{Fe}$ and $\mathrm{Cu}$ compounds had an enhancing effect $[6,7]$.

Based on previous findings, Toyota Motors developed a new engine oil product that could reduce low speed pre-ignition LSPI frequency by $10 \%$ compared to conventional ILSAC certified gasoline engine oils. It was tested for over 200 hours through oil degradation test and had maintained an excellent performance [8]. Previously, Japan Energy and Toyota Motors Corporation evaluated the performances of magnesium detergents in engine oil with a different combination of oil additives, and their results showed additional issue of concern with its use because of needle crystal formation and gelation $[9,10]$. Similar researches [11-14] have been studied to investigate the effect of additives in engine oil in an effort to reduce the PI event.

Instead of focusing on the metal additives, the authors in this work investigated the effect of alcohol, toluene and water addition in commercial lubricant oil without extensively altering its lubricity property. A few studies have investigated lubricant oil contaminated with ethanol, methanol and water. For instance, A.L. Bandera et al. [15] compared wear and friction behavior of ethanol-oil (5\% - 95\%) blend with engine oil and reported no significant difference. Also, E. Harika et al. [16] dissolved $1 \%$ to $7 \%$ water by mass in lubricating oil and showed that the dissolved water increased oil viscosity. Moreover, P. R. De Silva et al. [17] reported that the presence of ethanol and water in a fully formulated lubricant oil reduced friction. Another study showed that the increase in friction because of water contamination in an automatic transmission fluid was only a short period effect as the friction was reduced over long period [18].

Hence, the aim of this study is to determine ignition characteristics and the effect of alcohols, toluene and water addition in lubricant oil to lower its auto-ignition tendency as compared to pure lubricant oil so that the chances of pre-ignition occurrence can be lowered. Usually PI occurs 0 to 20 crank angle degree (CAD) before firing the spark plug. The equivalent time for an engine running at $2000 \mathrm{rpm}$ to travel 10 degrees crank angle is about $0.83 \mathrm{~ms}$. Considering the aforementioned $\mathrm{CAD}$, the equivalent time where PI occurs in an engine ranges from $0.083 \mathrm{~ms}$ to $1.667 \mathrm{~ms}$. The whole idea of this study is to determine if the ignition of the mixture can be delayed by $1.7 \mathrm{~ms}$ to ensure that the only source of ignition inside the engine is from firing the spark plug. 


\section{Experimental Set-up}

Experiments were conducted in two different types of constant volume combustion chambers where both their physics for combustion is different. A KAUST Research Ignition Quality Tester (KR-IQT) purchased from AET, Ltd. was used to determine the derived cetane number and ignition delay time (IDT) of the mixtures. Similarly, a pre-ignition vessel which was explicitly designed to study the auto-ignition behavior of a single droplet in elevated temperatures and pressures was used to determine the time to ignition (TI) of the mixtures. The mixture is sprayed in the IQT while a single droplet is injected and suspended in the PI vessel. The detailed descriptions of the used apparatus are given below.

\section{Pre-Ignition (PI) vessel}

The pre-ignition vessel made of stainless steel $316 \mathrm{~L}$ material has a length of $320 \mathrm{~mm}$ and wall thickness of $3 \mathrm{~cm}$. It has a volume of $4 \mathrm{~L}$ and has been pressure tested up to 70 bar via the hydrostatic testing method. It can be operated in wide temperature ranges from room temperature to $500{ }^{\circ} \mathrm{C}$. It is equipped with three orthogonal pairs of quartz windows for optical diagnostics. The schematic of pre-ignition vessel is shown in Figure 2.

Multiple heating sources such as an in-line heater (Watlow) with a power rating of $3 \mathrm{~kW}$ and four heating tapes (Omega STH052-100) with a power rating of $0.738 \mathrm{~kW}$ each were fitted for heating the vessel to the required initial temperature. The experiments were carried out at an initial temperature of $300 \pm 4{ }^{\circ} \mathrm{C}$ and initial pressures ranging from 4 bar to 22 bar at 6 bar pressure interval. A single droplet generator was designed and incorporated in the vessel for simulating the droplet-induced pre-ignition. This design has the capacity to water cool the capillary tube residing inside a cooling chamber assembly. The cold water temperature was set at $10{ }^{\circ} \mathrm{C}$ in order to prevent the droplet from evaporating or igniting before it was injected on a K-type thermocouple bead. This makes it possible to monitor the instantaneous droplet temperature throughout the droplet lifetime from suspension to ignition to complete consumption. The sample mixture is delivered to the capillary tube via a precise syringe pump (Harvard Apparatus PHD 2000) with an accuracy of $\pm 1 \%$ and reproducibility of $\pm 0.1 \%$. The piston's movement inside the actuator cylinder is controlled by pneumatic solenoid valves (Peter Paul electronics co. EH22H90CCH6).

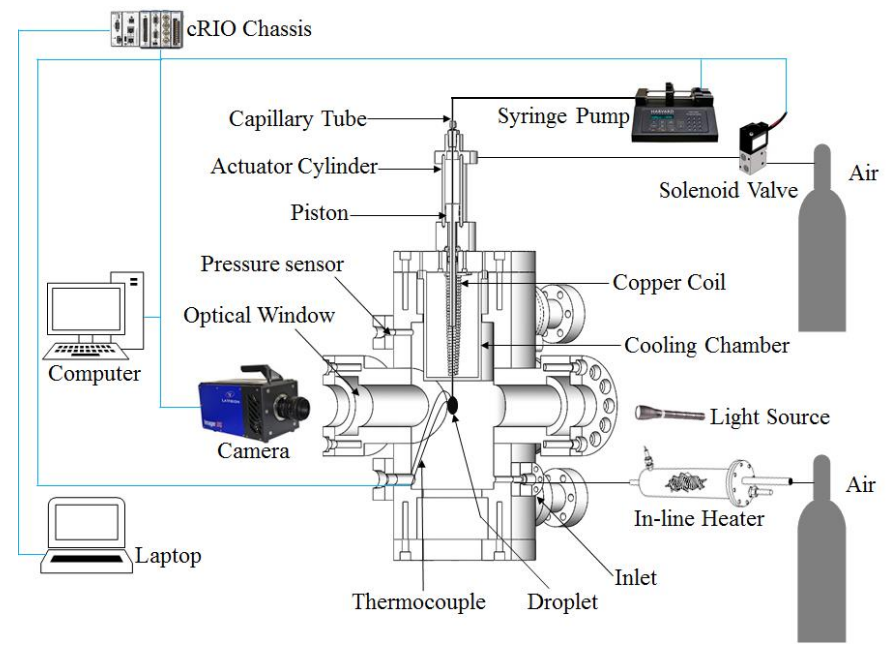

Figure 2. Schematic of pre-ignition vessel with exaggerated droplet size.
A shadowgraph technique is adapted for recording the droplet ignition phenomena using a high-speed camera (PCO, Imager Pro $\mathrm{HS}, 4 \mathrm{M})$ at the frame rate of $500 \mathrm{fps}$. Once the vessel reaches the desired conditions, the piston is extended into the chamber for $1 \mathrm{~s}$. The extension of piston and camera trigger process are synchronized and starts at the same time. Following this, the syringe pump injects the fuel/mixtures to form a droplet $(1.5 \pm 0.1 \mathrm{~mm}$ in diameter). The residence time of capillary tube in the hot environment is $1 \mathrm{~s}$ as well. After the suspension of droplet, the piston is retracted to the cooling chamber. This whole mechanism of extension, injection, retraction and recording of the images are automated via program developed with LabView software. The temperature measurement with elapsing time is also saved by this software simultaneously in real-time. Each droplet measurement was repeated multiple times to determine repeatability.

\section{KAUST Research Ignition Quality Tester (KR-IQT)}

The KR-IQT has a volume of $0.21 \mathrm{~L}$ and can be operated up to 22.4 bar initial charge pressure. It can be used for wide temperature ranges from $400{ }^{\circ} \mathrm{C}-585{ }^{\circ} \mathrm{C}$. The chamber comprises of fuel reservoir, variable displacement pump (VDP), fuel injector, cooling system for pressure transducer and injector nozzle tip, electric heaters, piezoelectric pressure transducer, and needle lift sensor. A schematic of KR-IQT is shown in Figure 1.

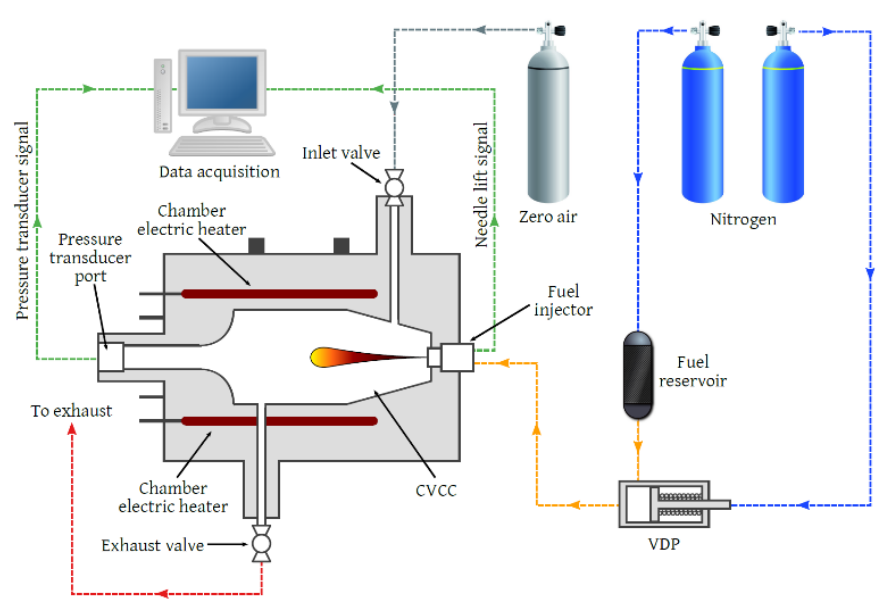

Figure 1. Schematic of KR-IQT.

The experiments were performed following ASTM D6890 method. The chamber was pressurized with air at 21 bar. The test temperature was set such that the IDT of n-heptane was observed to be $3.78 \pm 0.03$ $\mathrm{ms}$ which was seen at the set temperature of $550 \pm 2{ }^{\circ} \mathrm{C}$ for this study. While conducting the experiments, the temperature of the injector nozzle tip was recorded to be around $52{ }^{\circ} \mathrm{C}$ as it was water-cooled for the whole duration. A single-hole pintle type injector nozzle meeting the requirement of ISO 4010 was implemented for injection of fuel into the chamber. Each run consisted of 15 pre-injection to stabilize the chamber's ambient environment for the following 32 main injections. The data acquisition system recorded the main injections data which were averaged to get analytic IDT and DCN of the sample fuels. The parametric study for temperature was performed to investigate its impact on DCN and IDT.

To study the effect of fuel dilution in lubricant oil, and engine oil SAE15W40 was mixed with ethanol, methanol, toluene, and water at different concentration, see table 1 .

Page 2 of 7 


\begin{tabular}{|c|c|c|c|c|}
\hline & $\begin{array}{c}\text { Lub Oil } \\
(\%)\end{array}$ & $\begin{array}{c}\text { Ethanol } \\
(\%)\end{array}$ & $\begin{array}{c}\text { Methanol } \\
(\%)\end{array}$ & $\begin{array}{c}\text { Water } \\
(\%)\end{array}$ \\
\hline L100 & 100 & - & - & - \\
\hline L99E1 & 99 & 1 & - & - \\
\hline L98E2 & 98 & 2 & - & - \\
\hline L97E3 & 07 & 3 & - & - \\
\hline L96E4 & 96 & 4 & - & - \\
\hline L99E5 & 95 & 5 & - & - \\
\hline L99M1 & 99 & - & 1 & - \\
\hline L98M2 & 98 & - & 2 & - \\
\hline L97M3 & 97 & - & 3 & - \\
\hline L96M4 & 96 & - & 4 & - \\
\hline L95M5 & 95 & - & 5 & - \\
\hline L99T1 & 99 & - & - & - \\
\hline L98T2 & 98 & - & - & - \\
\hline L97T3 & 97 & - & - & - \\
\hline L96T4 & 96 & - & - & - \\
\hline L95T5 & 95 & - & - & - \\
\hline L98E1W1 & 98 & 1 & - & 1 \\
\hline L90E5W5 & 90 & 5 & - & 5 \\
\hline L98M1W1 & 98 & - & 1 & 1 \\
\hline L90M5W5 & 90 & - & 5 & 5 \\
\hline
\end{tabular}

\section{Defining time of ignition (TI) for PI vessel}

The PI Vessel is not a standardized vessel and thus is required to define its specific time of ignition (TI), which is different from IDT obtained with KR-IQT. The temperature history of the droplet ignition for 95 vol. \% lubricant oil and 5 vol. \% toluene in air environment at $304{ }^{\circ} \mathrm{C}$ temperature and 10 bar pressure is shown in figure 3 . The thick black line represents the average temperature of 10 experiments while the grey vertical fringe represents the standard deviation of these experiments.

As seen in figure 3 , the thermocouple reads the initial temperature of the ambient air until the mixture is injected into the thermocouple bead. Since the mixture resides inside a cooling chamber until the time of injection, the initial droplet temperature is much lower than that of ambient air temperature inside the vessel. Once the droplet comes in contact with the thermocouple bead, a gradual drop in temperature can be observed. When the droplet is successfully suspended, the thermocouple now measures its internal temperature resulting in a steeper drop in temperature until it reaches a minimum temperature (A). The plot is offset such that the minimum temperature (A) in lines with time at zero. The size of the droplet shrinks because of evaporation occurring on its surface. Due to internal conduction, heat is transferred from the surface to the droplet's interior core. With increasing evaporation rate, the internal droplet temperature increases as well until the time it ignites (B) which is triggered by ignition of the mixture's vapor surrounding the droplet. This is followed by a rapid increase in temperature until it reaches its maximum, where the droplet is completely consumed. The temperature gradually decreases to the initial ambient air temperature after this process.

Hence, TI is defined as the time interval between the local minimum temperature (A) and the time where the ignition of the droplet first occurs (B). This is indicated by the rapid increase of dT/dt obtained from temperature history. The term TI is used instead of the IDT since the temperatures recorded are not the temperature of the auto igniting stoichiometric vapor but is rather the droplet interior temperature. The TI defined by this method should be longer than the IDT of the mixture obtained with KR-IQT. Although the TI obtained from the current experiments may overshoot the IDT, it can, however, show the trend of IDT of pre-ignition events of all tested mixtures.

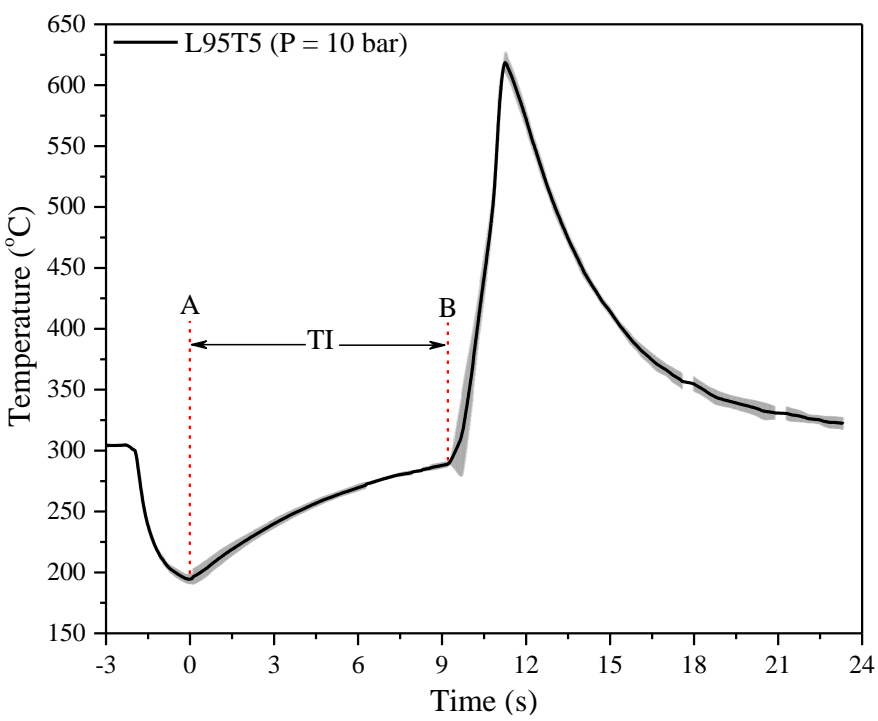

Figure 3. Defining time of ignition (TI) for PI Vessel.

\section{Result and Discussion}

\section{Effect of concentration of fuel dilution in lubricant oil ignition phenomena.}

A commercial engine oil (SAE15W40) was mixed with toluene/ethanol and water by vol \%. The ignition characteristics of these mixtures were observed using the PI vessel by suspending a single droplet on a thermocouple bead. The ignition behavior of these mixtures was then compared with the ignition behavior of pure lubricant oil as shown in figure 4. Once the droplet is suspended successfully and reaches the minimum temperature, the temperature then starts to increase gradually where the components of mixture evaporate and mix with the surrounding hot air. This air and vapor mixture triggers an ignition when it reaches its flammability range.

Page 3 of 7 


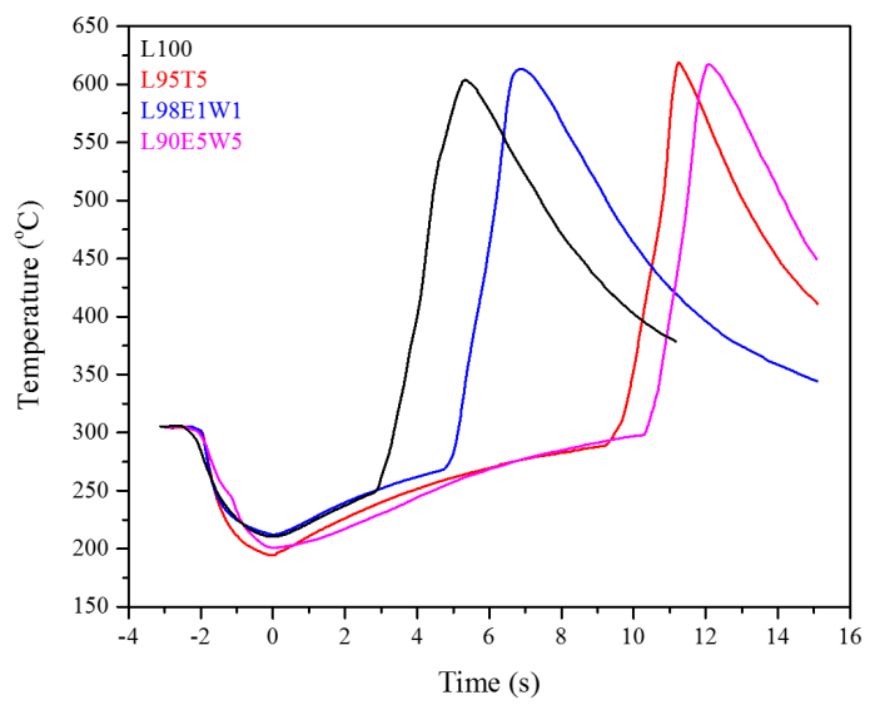

Figure 4. The temperature history of lubricant oil mixed with toluene/ethanol and water at 10 bar pressure.

The time of ignition (TI) includes both the physical and chemical delay. As shown in figure 5 and figure 6 , the physical delay is dominant over the chemical delay. It takes roughly $17 \mathrm{~s}$ to vaporize while the combustion itself lasts for about $3.5 \mathrm{~s}$ only. As observed in figure 4, engine oil ignited earlier compared all tested mixtures.

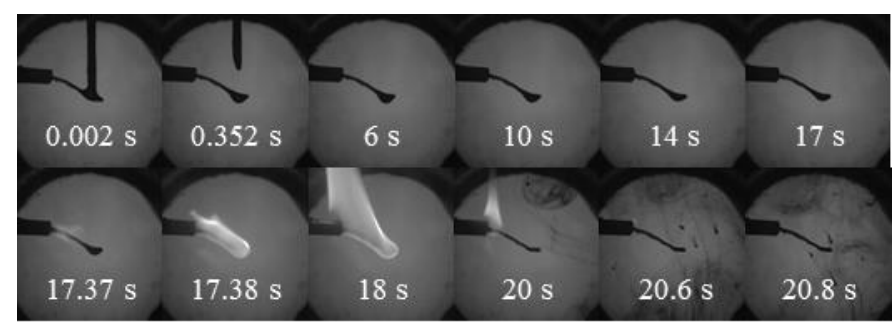

Figure 5. Ignition sequence of L95T5 at 4 bar pressure.

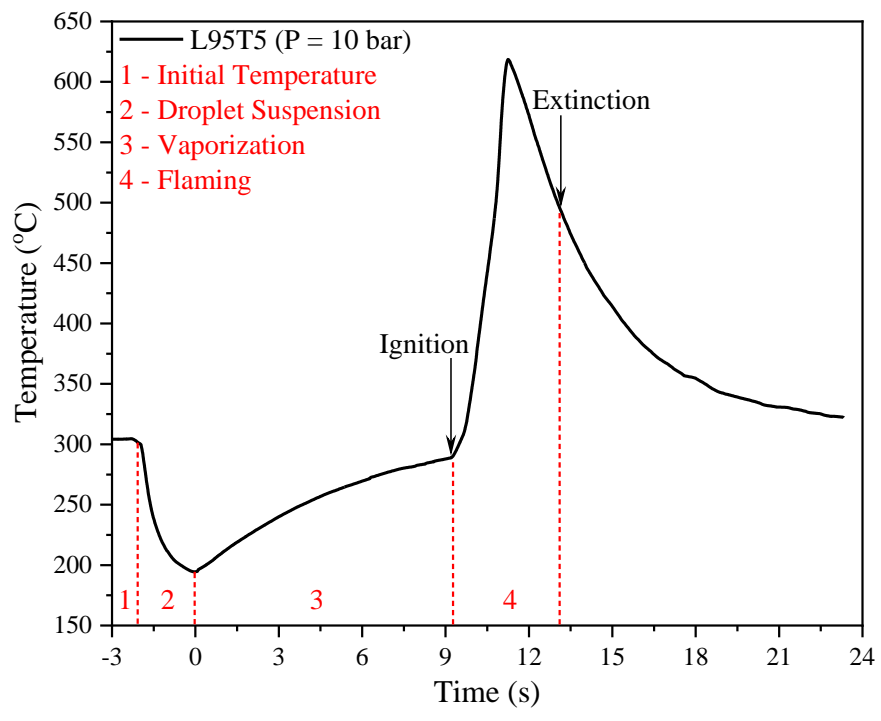

Figure 6. Temperature history showing combustion steps.
Effect of pressure in lubricant oil ignition phenomena.

In order to study the effect of pressure, further experiments were conducted for 95 vol. \% lubricant oil mixed with 5 vol. \% toluene (L95T5) and compared with the ignition characteristics of pure lubricant oil (L100). For all the set pressure, L100 ignited earlier compared to L95T5 mixture. At lower pressure regime, the time gap for the mixture to ignite was observed to be longer (Figure 7). In contrast, with the increasing pressure, the time gap for mixtures to ignite narrowed down. It is also worth noting that the change in TI for L100 at pressures higher than 16 bar is very similar while the change in TI for L95T5 for all pressures is significant.

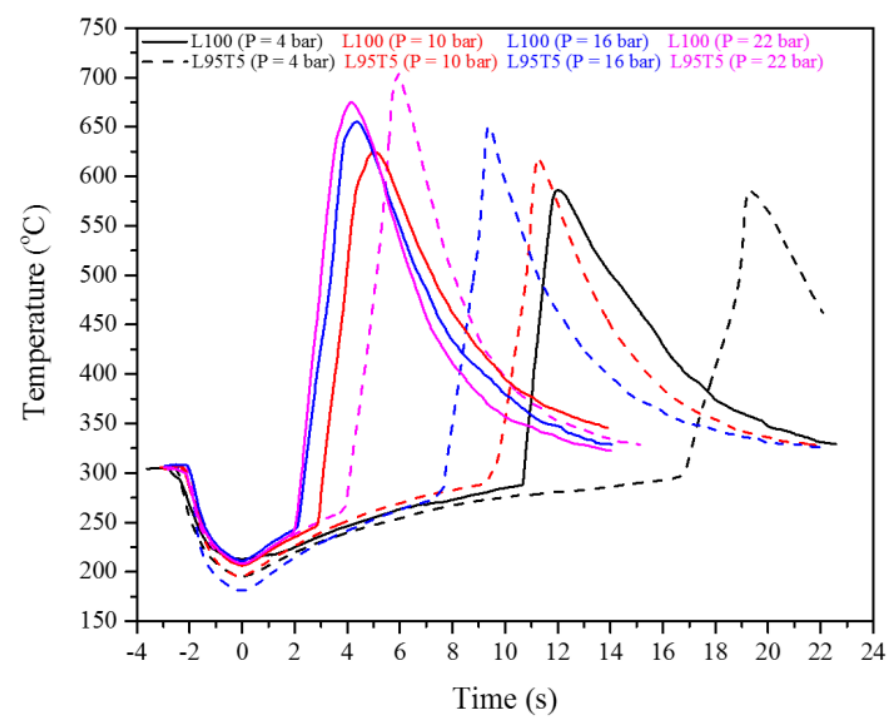

Figure 7. The temperature history of L100 and L95T5 at different pressure.

Figure 8 shows the effect of pressure on the ignition of a suspended single droplet (mixture) at $300{ }^{\circ} \mathrm{C}$ in an air environment. Each point presented in the plot is an average of 10 experiments. The TI decreased with the increase in pressure, and this effect is decreased at higher pressure.

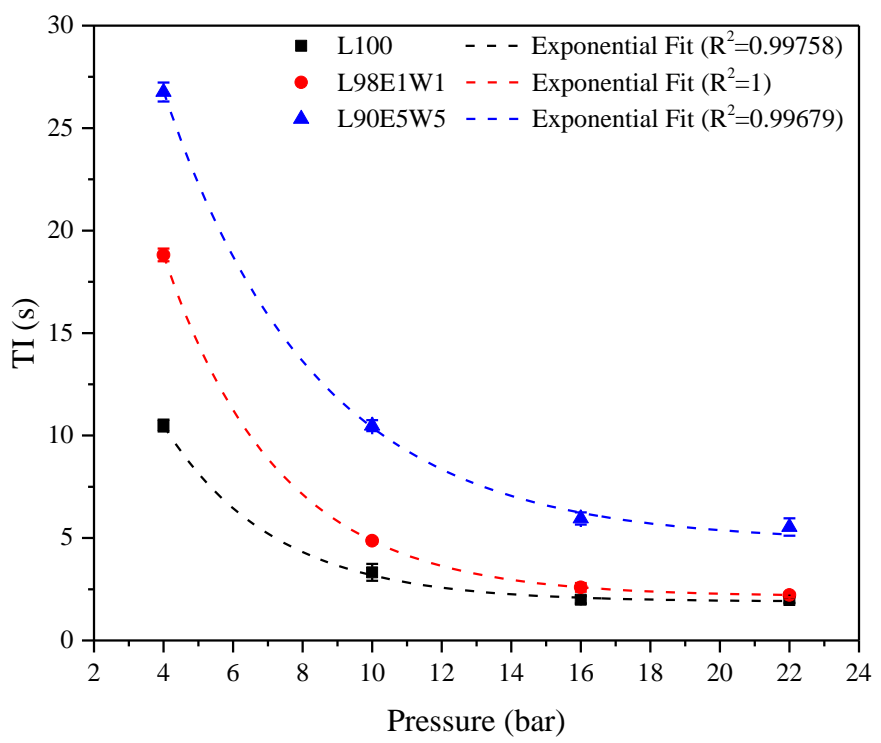

Figure 8. TI of different mixtures at different pressures measured in PI Vessel.

Page 4 of 7 
Addition of $1 \%$ water and $1 \%$ ethanol almost doubled the TI at 4 bar pressure compared to pure lubricant oil. However an asymptotic behaviour is observed at pressures higher than 16 bar. For L90E5W5 case, the change in TI is more apparent event at higher pressure. Since it is important to know the DCN as well as the IDT of the mixtures following standard method, further experiments were conducted for the mixtures listed in Table using KR-IQT. It was also desirable to investigate the trends obtained from PI vessel and KRIQT.

\section{Effect of alcohols and toluene dilution in lubricant oil.}

Lubricant oil was mixed with ethanol, methanol and toluene at $1 \%$ $5 \%$ by vol. as listed in Table 1 investigating their effect in DCN and IDT of the mixtures. As shown in figure 9, with increasing concentration of alcohol in lubricant oil, the IDT increases as well. Adding methanol by $5 \%$ vol. yielded the highest IDT. Both the alcohols follow the exponential trend for IDT. In the other hand, the addition of toluene up to $2 \%$ by vol., showed increased in IDT after which further addition resulted in decrease in IDT.

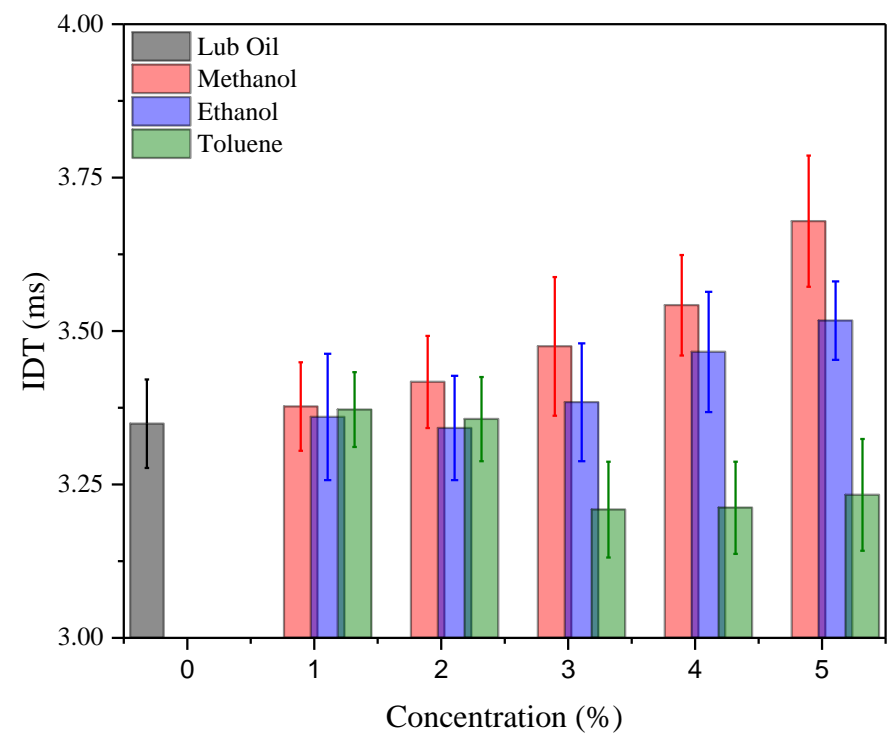

Figure 9. IDT of different mixtures at different concentration (ASTM D6890).

IDT of methanol is observed to be highest followed by ethanol and toluene respectively. This can be attributed to the enthalpy of vaporization. Since toluene has the lowest enthalpy of vaporization $(351 \mathrm{~J} / \mathrm{g})$, the in-cylinder temperature reduction is low when compared to alcohol addition, leading to a more reactive atmosphere. In contrast, enthalpy of vaporization of methanol $(1100 \mathrm{~J} / \mathrm{g})$ is highest amongst the molecules used in the study, thereby cooling the charge more effectively, leading to longer IDT.

On the other hand, alcohol addition decreased DCN for the mixtures in contrast to toluene. Lubricant oil diluted with methanol at $4 \%$ and $5 \%$ by vol. decreased the mixtures DCN by $4.5 \%$ and $7.8 \%$ respectively as shown in Figure 10. Similarly, ethanol diluted at $4 \%$ and $5 \%$ by vol. decreased mixtures DCN by $2.6 \%$ and $4.5 \%$ respectively.

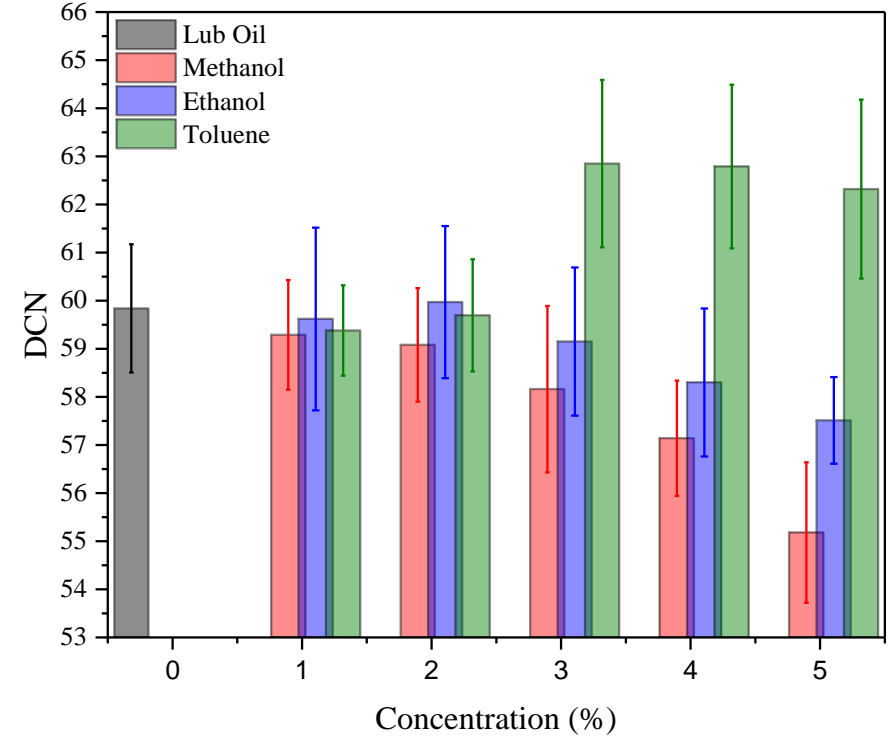

Figure 10. DCN of different mixtures at different concentration (ASTMD6890)

A mixture with higher DCN has a higher tendency to auto-ignite in a spark-ignition engine. Auto-ignition of end-gas ahead of a sparkinitiated flame front leads to unwanted knock. Diluting commercial lubricant oil with an appropriate amount of alcohol without changing its lubricity property by much, might delay the auto-ignition of lubricant oil droplet. Lubricant-fuel mixture droplets may escape from the liner to the combustion chamber and auto-ignite, causing pre-ignition. In such a case, the auto-ignition tendency of this mixture becomes critical. Hence these components of fuels when added to lubricant oil will increase the IDT of mixture and is less likely to cause pre-ignition.

\section{Effect of temperature as measured in KR-IQT.}

In another set of experiments, temperature were varied in KR-IQT to observe its effect in DCN and IDT as shown in figure 11.

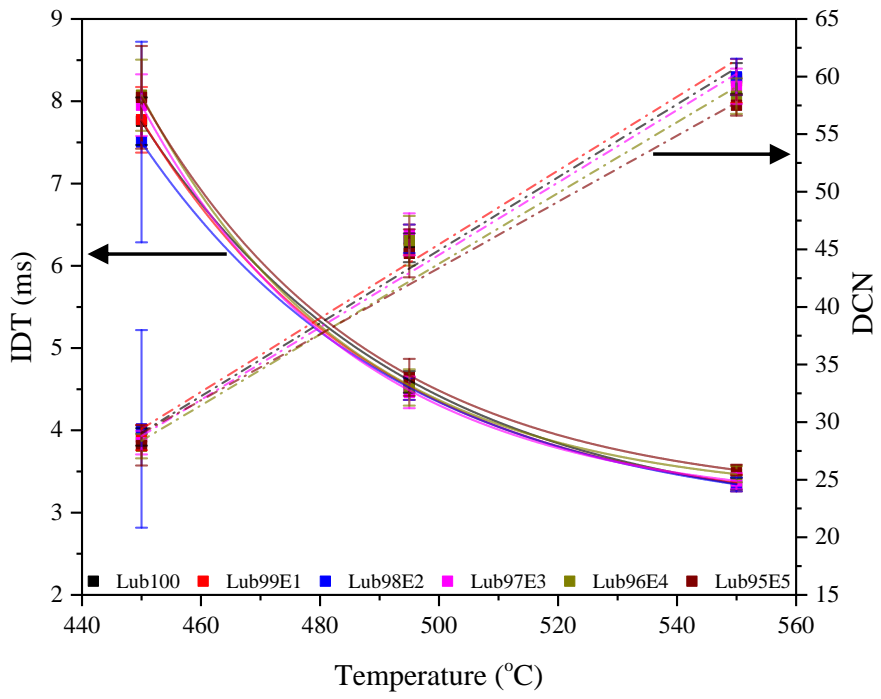

Figure 11. IDT and DCN of different mixtures at different temperatures.

Page 5 of 7 
These experiments were performed for lubricant oil and ethanol mixtures at different concentration ( $1 \%-5 \%$ by vol.). From figure 11 , it can be observed that IDT of these mixtures decreased exponentially as the temperature increased which was expected. Similarly, a linear increase in DCN can be observed with increasing temperature.

\section{Effect of water and ethanol addition in lubricant oil.}

Results obtained for the same mixtures in KR-IQT following ASTM D6890 method and PI vessel at 4bar, 10 bar, 16 bar, and 22 bar pressure are shown in figure 12 and 13 respectively.

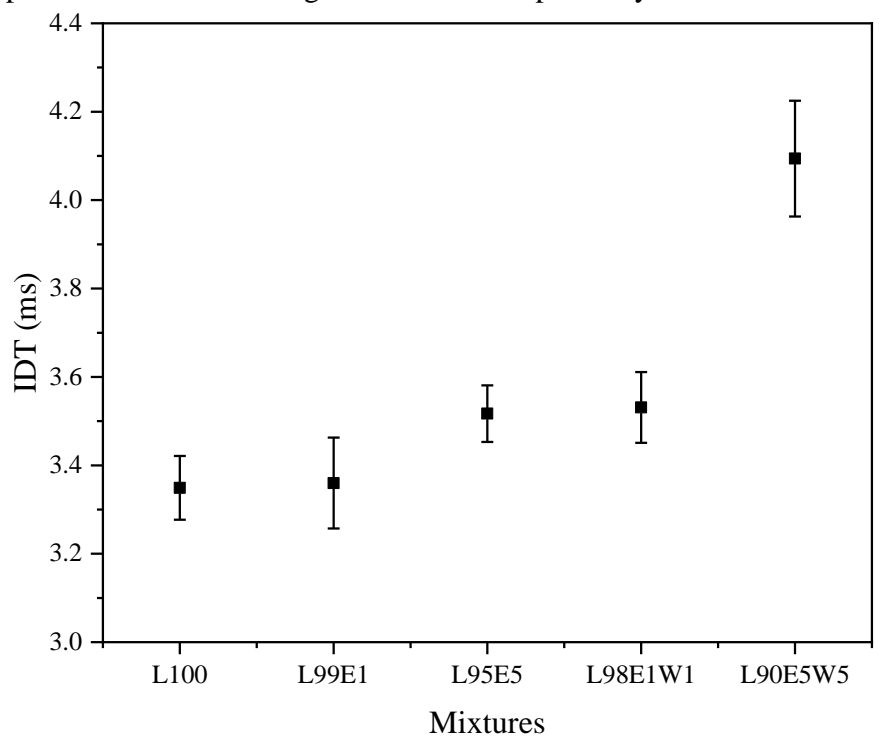

Figure 12. IDT for lubricant oil diluted with ethanol and water.

Similar trends can be observed for both experiments exhibiting a good agreement. Even though L90E5W5 has the longest IDT/TI, it will be a great challenge to maintain the lubricity property of lubricating oil at that high concentration of water and ethanol addition. Therefore, it is more desirable to use L98E1W1 as its lubricity property will not be altered by a great extent.

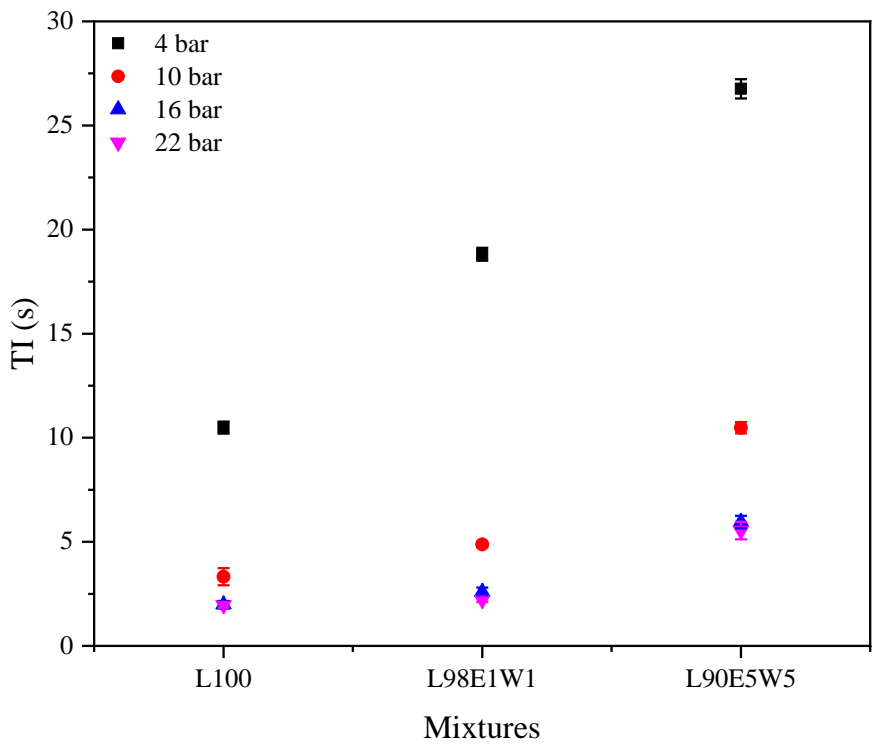

Figure 13. TI for lubricant oil diluted with ethanol and water.

Page 6 of 7

\section{Conclusions}

Experiments were conducted the PI vessel to investigate the ignition characteristics of mixture droplet. Similarly, KR-IQT was used to determine the standardized IDT and DCN and investigate their influence in the mixture. Commercial lubricant oil (SAE15W40) was mixed with different alcohols, toluene and water at a different concentration to study their effect on lubricant oil's DCN and IDT. The key findings are summarized here:

- Lubricant oil diluted with methanol at $4 \%$ and $5 \%$ by vol. decreased the mixtures DCN by $4.5 \%$ and $7.8 \%$ respectively resulting in obtaining a higher IDT.

- Similarly, ethanol diluted at $4 \%$ and $5 \%$ by vol. decreased mixtures DCN by $2.6 \%$ and $4.5 \%$ respectively. It is worth noting that methanol addition at $4 \%$ by vol. and ethanol addition at $5 \%$ yielded approximately the same IDT and DCN.

- When the temperature was varied between $\left(550{ }^{\circ} \mathrm{C}-450{ }^{\circ} \mathrm{C}\right)$ in KR-IQT, an exponentially increasing trend was observed for the mixtures IDT while a linearly decreasing trend was observed for the mixtures DCN with decreasing temperature.

- IDT of methanol was observed to be highest followed by ethanol and toluene respectively. This can be attributed to the enthalpy of vaporization.

- When $1 \%$ water and $1 \%$ were added to ethanol, TI at 4 bar pressure was almost twice as compared to pure lubricant oil. However, an asymptotic behavior is observed at pressures higher than 16 bar. For L90E5W5 case, the change in TI is more apparent event at higher pressure.

- Both KR-IQT and PI vessel showed similar trends when water and ethanol were added in lubricant oil.

- $\quad$ L90E5W5 had the highest IDT/TI; however L98E1W1 might be more desirable to be mixed with lubricant oil in order to get longer IDT without altering its lubricity property by great extent.

\section{References}

[1] N. Sasaki, K. Nakata, Effect of fuel components on engine abnormal combustion, Report No. 0148-7191, SAE Technical Paper, 2012.

[2] M. Amann, D. Mehta, T. Alger, Engine operating condition and gasoline fuel composition effects on low-speed pre-ignition in highperformance spark ignited gasoline engines, SAE International Journal of Engines 4 (2011) 274-285.

[3] M. Amann, T. Alger, Lubricant Reactivity Effects on Gasoline Spark Ignition Engine Knock, SAE International Journal of Fuels and Lubricants 5 (2012) 760-771.

[4] C. Dahnz, K.-M. Han, U. Spicher, M. Magar, R. Schieß1, U. Maas, Investigations on pre-ignition in highly supercharged SI engines, SAE International Journal of Engines 3 (2010) 214-224.

[5] M. Ohtomo, H. Miyagawa, M. Koike, N. Yokoo, K. Nakata, Preignition of gasoline-air mixture triggered by a lubricant oil droplet, SAE International Journal of Fuels and Lubricants 7 (2014) 673-682.

[6] K. Takeuchi, K. Fujimoto, S. Hirano, M. Yamashita, Investigation of engine oil effect on abnormal combustion in turbocharged direct injection-spark ignition engines, SAE International Journal of Fuels and Lubricants 5 (2012) 1017-1024.

[7] S. Hirano, M. Yamashita, K. Fujimoto, K. Kato, Investigation of Engine Oil Effect on Abnormal Combustion in Turbocharged Direct Injection-Spark Ignition Engines (Part 2), Report No. 0148-7191, SAE Technical Paper, 2013.

[8] K. Fujimoto, M. Yamashita, S. Hirano, K. Kato, I. Watanabe, K. Ito, Engine oil development for preventing pre-ignition in 
turbocharged gasoline engine, SAE International Journal of Fuels and Lubricants 7 (2014) 869-874.

[9] N. Naganuma, G. Ogino, T. Kikuchi, K. Akiyama, A mechanism for the needle crystal formation from magnesium detergents in engine oils, JSAE Review 17 (1996) 121-125.

[10] Y. Naitoh, N. Naganuma, K. Akiyama, H. Sagami, The Establishment of Laboratory Test Method for Gelation of Engine Oil Containing Magnesium Detergents, SAE International, 2001.

[11] E.M. Chapman, V.S. Costanzo, A Literature Review of Abnormal Ignition by Fuel and Lubricant Derivatives, SAE International Journal of Engines 9 (2016) 107-142.

[12] L. Gibbs, Gasoline additives-when and why, SAE transactions, (1990) 618-638.

[13] S. Maharjan, Y. Qahtani, W. Roberts, A. Elbaz, The Effect of Pressure, Temperature and Additives on Droplet Ignition of Lubricant Oil and Its Surrogate, Report No. 0148-7191, SAE Technical Paper, 2018.

[14] L.G. Pless, Surface Ignition and Rumble in Engines: A Literature Review, SAE Transactions, (1966) 293-314.

[15] A.L. Bandeira, R. Trentin, C. Aguzzoli, M.E.H. Maia da Costa, A.F. Michels, I.J.R. Baumvol, M.C.M. Farias, C.A. Figueroa, Sliding wear and friction behavior of $\mathrm{CrN}$-coating in ethanol and oil-ethanol mixture, Wear 301 (2013) 786-794.

[16] E. Harika, M. Hélène, J. Bouyer, M. Fillon, Impact of lubricant contamination with water on hydrodynamic thrust bearing performance Impact de la pollution des lubrifiants par de l'eau sur les performances d'une butée hydrodynamique.

[17] P. De Silva, M. Priest, P. Lee, R. Coy, R. Taylor, Tribometer investigation of the frictional response of piston rings when lubricated with the separated phases of lubricant contaminated with the gasoline engine biofuel ethanol and water, Tribology Letters 43 (2011) 107-120.

[18] N. Fatima, A. Holmgren, P. Marklund, I. Minami, R. Larsson, Degradation mechanism of automatic transmission fluid by water as a contaminant, Proceedings of the Institution of Mechanical Engineers, Part J: Journal of Engineering Tribology 229 (2015) 74-85.

\section{Contact Information}

Ayman Elbaz

Ayman.elhagrasy@kaust.edu.sa

$+966544701524$

\section{Acknowledgments}

This project is supported by Saudi Aramco under the FUELCOM II project and the Clean Combustion Research Center, King Abdullah University of Science and Technology (KAUST).

\section{Definitions/Abbreviations}

IDT Ignition delay time

DCN Derived cetane number

KR-IQT KAUST research ignition quality tester

CVCC Constant volume combustion chamber

TI

Time of ignition
PI

Pre-ignition

CAD Crank angle degree

LSPI Low speed pre-ignition

Page 7 of 7

10/19/2016 